\section{P123 IMPULSE OSCILLOMETRY (IOS) INDICES IN SEVERE ASTHMA AND HEALTHY CONTROLS AFTER DEEP BREATH MANOEUVRES AND BRONCHODILATOR ADMINISTRATION}

doi:10.1136/thx.2010.150987.24

I Umar, D Desai, S Corkill, M Shelley, A Singapuri, C Brightling, S Siddiqui. University of Leicester, Leicester, UK

Introduction Impulse oscillometry is a non-invasive method used to measure airway impedance. There is increasing interest in utilising frequency dependence of airway resistance/reactance to study small airways disease in asthma. We examined frequency dependant behaviour in severe asthma and the response to deep inspiration and bronchodilators.

Methods 27 healthy controls (C) (Mean (sem) age; 48.4 (2.2), Sex M: F; 9:18, post-bronchodilator $\mathrm{FEV}_{1} \%$ predicted; 108.2 (2.8)\%) and 66 GINA stage 4-5 severe asthmatics (A) (Mean (Sem) age; 54.1 (1.4), Sex M:F; 31:35, post-bronchodilator FEV1\% predicted; 81.02(2.7)\%), were recruited from Glenfield Hospital, UK. Impulse oscillometry (IOS) was performed at 5-35 Hz, with impulses triggered every $0.2 \mathrm{~s}$ for $150 \mathrm{~s}$, at (1) baseline (base) (2) immediately after five deep breaths (TLC-RV) (pdb) (3) $15 \mathrm{~min}$ after $400 \mathrm{mcg}$ inhaled salbutamol (pbd). Markers of total (R5) and large airway (R20) resistance, and frequency dependant behaviour of resistance (R5-R20) and reactance area (AX) were evaluated. Triplicate measurements of $150 \mathrm{~s}$ were performed in 18 randomly selected asthmatics from our cohort to assess repeatability.
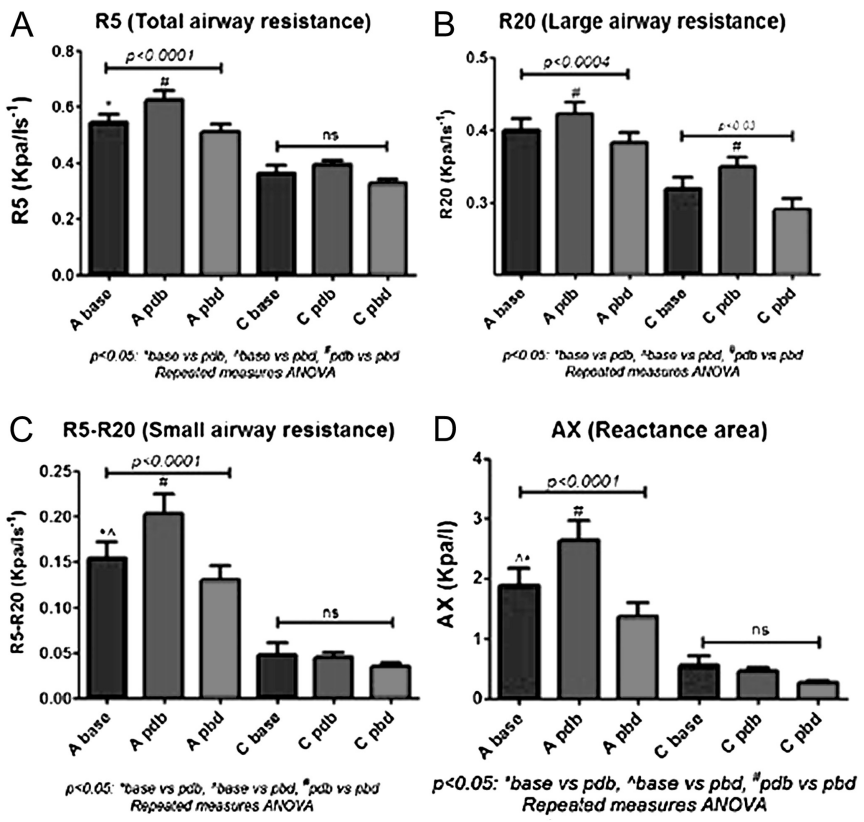

Abstract P123 Figure 1
Results Impedence measurements were highly repeatable (an intraclass correlation of 0.9 ) in the triplicate series. We observed asignificant increase in frequency dependence of both resistance (R5-R20) and reactance $(\mathrm{AX})$ after deep inspiration in asthma, but not in healthy controls, which was reversed by the use of a bronchodilator (Abstract P123 Figures 1A-D). In addition R20 increased in both severe asthma and healthy controls after deep inspiration.

Conclusions Deep inspiration significantly increased frequency dependence of resistance and reactance in severe asthma suggesting that the small airways may be related to the aberrant deep inspiratory response in severe asthma.

\section{P124 NEUROVENTILATORY UNCOUPLING DURING CYCLE AND TREADMILL EXERCISE IN COPD}

doi:10.1136/thx.2010.150987.25

${ }^{1} \mathrm{C} J$ Jolley, ${ }^{2} \mathrm{Y}$ M Luo, ' J Steier, ${ }^{1} \mathrm{G}$ Rafferty, ${ }^{3} \mathrm{M}$ I Polkey, ${ }^{1} \mathrm{~J}$ Moxham. ${ }^{1}$ King's College London, London, UK; ${ }^{2}$ State Key Laboratory of Respiratory Disease, Guangzhou, China; ${ }^{3}$ Royal Brompton Hospital, London, UK

Background It is widely accepted that neuroventilatory uncoupling drives breathlessness in COPD. COPD patients are more likely to stop exercising because of breathlessness during treadmill exercise than whilst cycling

Aim To test the hypothesis that patients exhibit higher levels of neuroventilatory uncoupling during treadmill exercise than whilst cycling.

Methods Diaphragm electromyogram $\left(\mathrm{EMG}_{\mathrm{di}}\right)$ and parasternal intercostal muscle EMG (EMGPS) activity were recorded in 12 COPD patients (mean (SD) age 66.7 (7.0) years, $\mathrm{FEV}_{1} 38.7$ (14.5)\% predicted, 11 male), during incremental cycle and treadmill exercise to exhaustion. For each muscle, the mean peak root mean square (RMS) EMG per breath over the final $30 \mathrm{~s}$ of each minute was normalised to peak RMS EMG recorded during maximal inspiratory manoeuvres, and corrected for inspiratory time and respiratory rate $\left(\mathrm{EMG}_{\mathrm{di}}\right.$ index, $\mathrm{EMG}_{\mathrm{PS}}$ index). Borg breathlessness was assessed every minute and at exhaustion.

Results $\mathrm{EMG}_{\mathrm{PS}}$ index and EMGPS activity per unit ventilation $\left(E M G_{P S}\right.$ index $\left./ V_{E}\right)$ were higher at exhaustion during treadmill exercise (Abstract P124 Table 1). A higher $\mathrm{V}_{\mathrm{E}}$ at exhaustion whilst cycling approached statistical significance. $\mathrm{EMG}_{\mathrm{di}}$ index and breathlessness were not significantly different at exhaustion when exercise modes were compared.

Conclusion $\mathrm{A}$ higher $\mathrm{EMG}_{\mathrm{PS}}$ index $/ \mathrm{V}_{\mathrm{E}}$ and lower $\mathrm{V}_{\mathrm{E}}$ at exhaustion during treadmill exercise suggest that neuroventilatory uncoupling is greater than during cycle exercise. This did not translate to greater breathlessness during treadmill exercise in this study, but warrants further investigation in a larger group of patients.

Abstract P124 Table 1 Ventilation, respiratory muscle activity and breathlessness at exhaustion during cycle and treadmill exercises

\begin{tabular}{|c|c|c|c|c|c|c|}
\hline & $V_{z}\left(L^{\prime} \min \right)$ & $\mathrm{EMG}_{41}$ index (a.u.) & $\mathrm{EMG}_{\mathrm{FB}}$ index (a.u.) & $\mathrm{EMG}_{41}$ index $N_{\mathrm{z}}$ (a.u.) & $\mathrm{EMG}_{\mathrm{F} 8}$ index $N_{\mathrm{c}}$ (a.u.) & Borg \\
\hline Cycle & $23.7(13.5-43.6)$ & $1213.0(866.5-1845.0)$ & $437.3(123.4-398.9)$ & $57.0(25.7-118.9)$ & $16.0(4.1-64.0)$ & $7(3-10)$ \\
\hline Tread-mill & $20.6(13.1-35,7)$ & $1365.0(762.4-1884.0)$ & $600.5(115.5-1414)$ & $67.5(23.9-104.2)$ & $27.9(4.6-98.0)$ & $7.5(4-10)$ \\
\hline $\mathrm{p}$ & 0.05 & 0.97 & 0.01 & 0.27 & 0.002 & 0.44 \\
\hline
\end{tabular}

Data are presented as median (range) and analysed using Wileoxon signed-rank tests.

$\mathrm{V}_{\mathrm{F}}$, minute ventilation; $\mathrm{EMG}$, electromyogram; $\mathrm{EMG}_{41}$, diaphragm electromyogram; $\mathrm{EMG}_{\mathrm{F} 8}$, parasternal intercostal muscle EMG; Borg, Borg breathlessness. 